\title{
Transgenic mice expressing bovine GH develop arthritic disorder and self-antibodies
}

\author{
S Ogueta ${ }^{1}$, I Olazabal ${ }^{1}$, I Santos ${ }^{2}$, E Delgado-Baeza ${ }^{2}$ and \\ J P García-Ruiz ${ }^{1}$ \\ ${ }^{1}$ Departamento de Biología Molecular, Centro de Biología Molecular-Severo Ochoa, Facultad de Ciencias (UAM-CSIC), Cantoblanco, 28049 Madrid, Spain \\ ${ }^{2}$ Residencia Sanitaria-La Paz, Departamento de Morfología, Facultad de Medicina (UAM), 28029 Madrid, Spain \\ (Requests for offprints should be addressed to J P García-Ruiz, Departamento de Biología Molecular, Centro de Biología Molecular-Severo Ochoa, \\ Facultad de Ciencias, Universidad Autónoma de Madrid, Cantoblanco, 28049 Madrid, Spain; Email: pgarcia@cbm.uam.es)
}

\begin{abstract}
We observed disability of movement in 6-month-old transgenic mice expressing the fusion gene coding for the bovine $\mathrm{GH}(\mathrm{bGH})$ under the transcriptional control of phosphoenolpyruvate carboxykinase promoter (PEPCKbGH). Histological study of the knee joint showed altered synovial and tibial articular cartilage tissues. In the cartilage the following observations were made: (i) generalized loss of the normal zonal structure and presence of clefts, and (ii) profound alterations in chondrocyte growth/ differentiation processes consistent with hypertrophy. The synovial tissue showed a reduced number of adipocytes, and a significant thickening of synovial lining tissue and pannus. These findings indicate that transgenic mice suffer damage to diarthritic joints with osteoarthritic appearance.
\end{abstract}

As changes in synovial membrane in osteoarthritis are almost indistinguishable from those seen in inflammatory arthritis, we determined the potential correlation with an immunological disorder. Serological determination of selfantibodies measured as a function of age and sex showed anti-nuclear, anti-single-stranded DNA, anti-doublestranded DNA and anti-70K antibodies, and an altered immunoglobulin typing. These results suggest that transgenic mice expressing bGH develop an arthritic process which is correlated with an immune disorder. The results also indicate that these mice are a suitable animal model to study the specific role of $\mathrm{GH}$-driven processes in immune cells and arthritis.

Journal of Endocrinology (2000) 165, 321-328

\section{Introduction}

Growth hormone $(\mathrm{GH})$ has long been recognized as being essential for somatic growth, differentiation, metabolism and thymic development (Clark 1997, Barkan 1992). The GH receptor (GHR) is a member of the cytokine/ haematopoietin family of receptors (Kelly et al. 1993). The availability of hormone-deficient mice has renewed the interest in the effect of hormones on functional lymphocytic response. Studies performed in the Snell dwarf $(\mathrm{dw} / \mathrm{dw})$ strain of mice, deficient in $\mathrm{GH}$, thyroidstimulating hormone (TSH), prolactin (PRL) and indirectly in insulin-like growth factor-I (IGF-I), revealed that their thymus was atrophied and their bone marrow was markedly hypocellular (Li et al. 1990, Murphy et al. 1992a). Later on, cytometric analysis showed that the production of $\mathrm{CD} 4^{+} \mathrm{CD} 8^{+}$thymocytes ceased at early ages in these mice, and that bone marrow $\mathrm{B}$ cell population showed depressed progenitor pool levels of CD45R ${ }^{+} /$ surface $\operatorname{IgM}^{-}$(Murphy et al. 1992b, Montecino-Rodríguez et al. 1996). This helps to explain the abnormally low numbers of marrow mononuclear cells in dwarf mice.
Studies carried out in IGF-I ${ }^{-{ }^{-}}$animals (Lin et al. 1993) and (lit/lit) mice that have a defect in the gene encoding the receptor for hypothalamic GH-releasing factor and consequently present low GH/IGF-I levels (PowellBaxton et al. 1993), support the notion of a general anabolic role of GH and IGF-I in thymus and bone marrow. When these mice were treated with IGF-I and $\mathrm{GH}$ respectively, the absolute number of marrow myeloid and $\mathrm{B}$ and thymic $\mathrm{T}$ cells increased. However, the relative increase was not significant taking into account the overall weight gain of the animals treated with GH and IGF-I (Montecino-Rodríguez et al. 1997). On the other hand, induction of lymphopoiesis and haematopoiesis in vivo and in vitro by GH and IGF-I has been demonstrated in a number of works (Clark 1997) and the expression of GHR and IGF-I receptor in immune cell system has been reported in human and murine species (Kooijman et al. 1995, Gagnerault et al. 1996, Mello-Coelho et al. 1998).

Transgenic ( $\mathrm{Tg}$ ) mice expressing $\mathrm{GH}$ from different species under different promoters have been generated (Frohman 1996). They present high systemic GH levels and in addition to increased skeletal growth, several other 
organs and systems are direct or indirect targets. They present renal pathology, diabetes, hypertension, sterility and several neuropathies (Quaife et al. 1989, Frohman 1996). However, the precise pathogenesis involved or whether the immune system is affected is still not known. The phenotypic characterization of lymphoid organs in 2-month-old phosphoenolpyruvate carboxykinase promoter (PEPCK-bGH) Tg mice has been reported (Gonzalo et al. 1996). Significant alterations in T-cell functions were observed, suggesting a potential role for $\mathrm{GH}$ in regulating the immune response. In addition, while T-cell subpopulations were found with minor changes, bone marrow was deprived of pre-B cells (Gonzalo et al. 1996).

In bGH Tg mice older than 6 months we observed disability of movement suggestive of the development of an arthritic process. Kidney damage, arthritic processes and the presence of self-antibodies are manifestations characteristic of an autoimmune disorder (Theofilopoulos \& Dixon 1985). Since bGH Tg mice develop glomerulosclerosis (Quaife et al. 1989), we considered it of interest to characterize the type of lesion of the knee joint and the status of the immune system. Histological determination of the knee showed profound alterations of the articular cartilage and synovial tissue resembling an arthritic process. Results of serologic determinations were consistent with the spontaneous development of an immunological disorder. The possible relationship between high GH levels and autoimmunity and the possibility that the articular alterations corresponded to an osteoarthritic or rheumatoid process are discussed. Our results suggest that bGH $\mathrm{Tg}$ mice are a suitable animal model to address the pathogenesis of arthritic processes and the mechanism by which sustained high GH/IGF-I levels cause immunological disorders. In addition, the side-effects described in humans following exogenous $\mathrm{GH}$ administration such as oedema and a subclinical activation of lupus nephritis (Yap et al. 1998) are related to the bGH Tg murine model.

\section{Material and Methods}

Animals

Transgenic mice were generated by M M McGrane (McGrane et al. 1990). The bGH Tg line was maintained by mating male transgenic animals with C57BL6 females for 15-18 generations (Gonzalo et al. 1996). Mice were reared under the classical barrier system in the animal house of the Centro de Biología Molecular. Transgenic mice showing increased body size were referred to as bGH $\mathrm{Tg}$ mice and were compared with litter mates of normal size referred to as control mice.

\section{Histologic studies}

Proximal tibia epiphyses were placed in 10\% formalin, decalcified at room temperature in a $0 \cdot 07 \%$ EDTA pH $7 \cdot 2$ solution for 24-48 $\mathrm{h}$ and processed for paraffin embedding. A series of $5 \mu \mathrm{m}$-thick sections were stained with haematoxylin-eosin (HE) following standard procedures. Sections were evaluated for the presence of inflammatory infiltrates, synovial proliferation and hyperplasia with or without exudates, fibrinoid inflammatory nodules, vasculitis, arteritis in periarticular and articular regions, and for chondrocyte differentiation stages (Mankin et al. 1994). Photographs were taken with an Oxford Trade photomicroscope, using Kodak TMAX 100 film.

\section{Immunoprecipitation and immunoblotting}

A $100 \mu \mathrm{l}$ volume of serum was diluted fourfold with PBS, adjusted to $1 \%$ Triton X-100 and incubated at $4{ }^{\circ} \mathrm{C}$ with $5 \mu \mathrm{g}$ of rabbit anti-mouse (RAM) (Nordic Immunology Laboratories, Tilburg, The Netherlands) bound to Protein A-Sepharose (Sigma, St Louis, MO, USA) for $1 \mathrm{~h}$. Immune complexes were washed as follows: three times with buffer A $(10 \mathrm{mM}$ Tris- $\mathrm{HCl}, \mathrm{pH} 7 \cdot 4,5 \mathrm{mM}$ EDTA, $50 \mathrm{mM} \mathrm{NaCl}, 1 \%$ Triton X-100, $1 \mathrm{mM}$ phenylmethylsulphonylfluoride, $2 \mathrm{mg} / \mathrm{ml}$ leupeptine and $0.5 \mathrm{mg} / \mathrm{ml}$ benzamidine), once with $0.5 \mathrm{M} \mathrm{LiCl}$, and twice with a buffer containing $10 \mathrm{mM}$ Tris- $\mathrm{HCl} \mathrm{pH} 7 \cdot 4,1 \mathrm{mM}$ EDTA, $100 \mathrm{mM} \mathrm{NaCl}$. The clean immune complexes were dissociated by addition of a twice-concentrated SDS-gel loading buffer and by boiling for $10 \mathrm{~min}$. Samples were analysed by SDS-PAGE. Gels were transferred to nitrocellulose (Schleicher and Schuell, Dassel, Germany). The nitrocellulose membranes were blocked at $37^{\circ} \mathrm{C}$ for $2 \mathrm{~h}$ with Tris-buffered saline (TBS) containing 5\% milk proteins and $0.05 \%$ Tween 20 . The blotted proteins were probed for $70 \mathrm{~K}$ by incubating overnight at $4{ }^{\circ} \mathrm{C}$ with $\mathrm{MAb}$ H111 (Kastner et al. 1992) (generously provided by Dr R Lührmann, Malburg, Germany) diluted 1:100 in TBS containing $5 \%$ non-fat BSA or milk proteins. The second antibody used for detection was an anti-mouse labelled with horseradish peroxidase. Blots were washed and developed using the enhanced chemiluminescence (ECL) system (Amersham Iberica, Madrid, Spain) according to manufacturer's instructions. Over 80 blood serum samples from bGH Tg mice were analysed. The percentage of animals presenting anti-70K antibodies was analysed on the basis of age and sex.

\section{Serological studies}

Anti-single-stranded DNA (ssDNA) and anti-doublestranded DNA (dsDNA) were measured by the enzymelinked immunosorbent assay (ELISA) method. Briefly, 96-well plates were doubly coated with $50 \mu$ poly-L-lysine at $25 \mathrm{mg} / \mathrm{ml}$ in PBS and subsequently with $50 \mu \mathrm{l}$ salmon sperm DNA or mouse DNA at $20 \mathrm{mg} / \mathrm{ml}$. Each coating step was carried out incubating at $37^{\circ} \mathrm{C}$ for $1 \mathrm{~h}$. Wells were then blocked with $300 \mu \mathrm{l}$ of $5 \%$ BSA in PBS at $37^{\circ} \mathrm{C}$ for $2 \mathrm{~h}$. Blocked wells were reacted with $50 \mu \mathrm{l}$ of $1 / 1000$ 

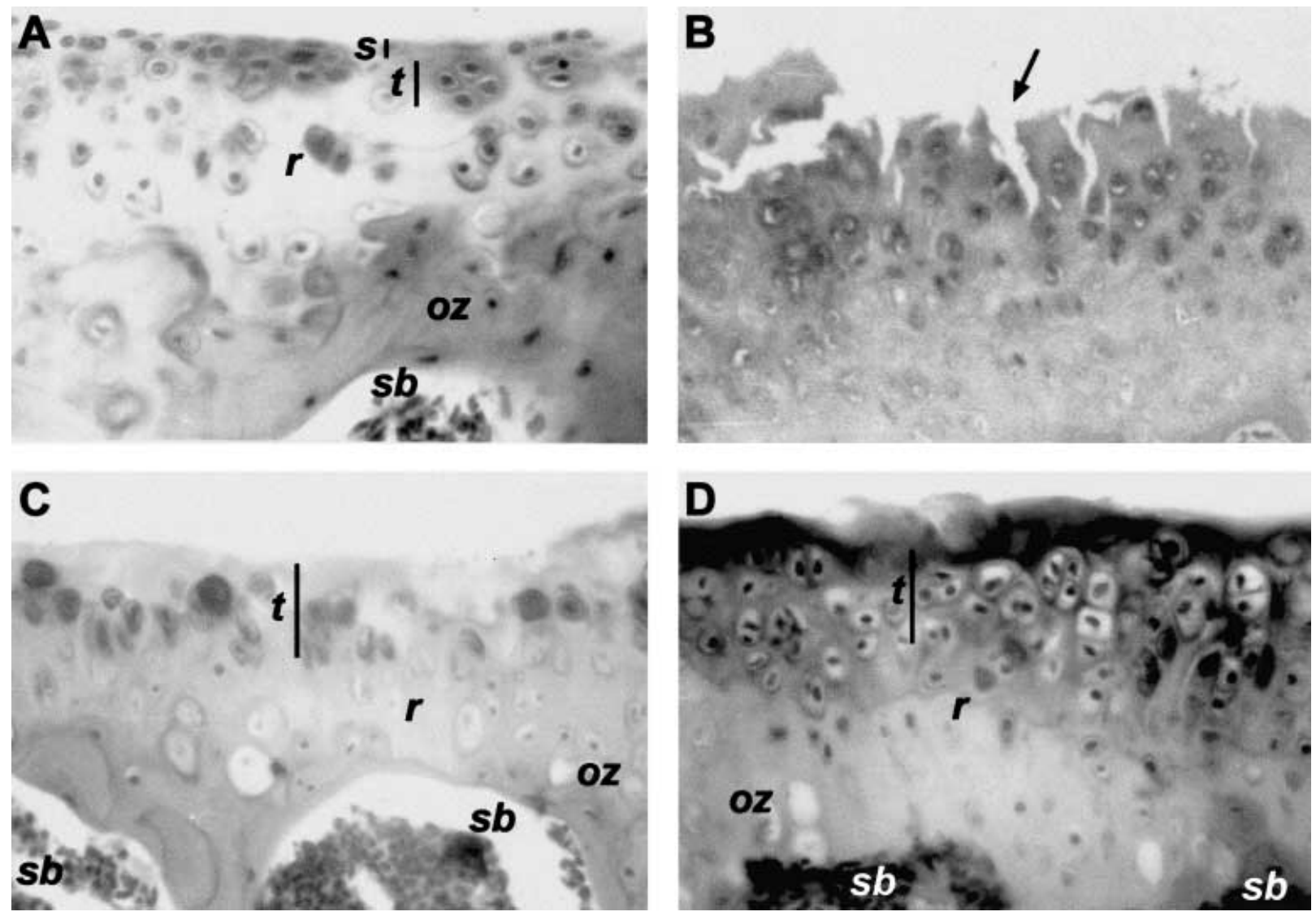

Figure 1 Cartilage examination. Articular cartilage of control mice (A) and bGH Tg mice (B, C, D). Cartilage of bGH Tg mice has frequent clefts (B). Transgenic mice show disorganized deep chondrocytes in the radial zone ( $r$ of $A$ versus $C$ and $D)$. Chondrocytes at the transitional zone show hyperthropy in bGH Tg mice ( $\mathrm{t}$ in A versus $\mathrm{C}$ and $\mathrm{D}$ ). Elongated chondrocytes at the superficial zone ( $\mathrm{s}$ in $\mathrm{A}$ disappear in bGH Tg mice (C and D). oz, osification zone; sb, subchondral bone. $\times 1000$ magnification.

serum at room temperature for $2 \mathrm{~h}$. Between incubations, wells were thoroughly washed with PBS-0.1\% Triton $\mathrm{X}-100$. The bound antibody was quantified using an anti-mouse antibody labelled with horseradish peroxidase. Peroxidase activity was measured using O-phenylenediamine (OPD) following the manufacturer's instructions (Sigma, St Louis, MO, USA). Mouse immunoglobulin isotypes were determined by ELISA using a Southern Biotechnology (Birmingham, AL, USA) kit. Goat antimouse $(\mathrm{L}+\mathrm{H})$ antibody at $10 \mathrm{mg} / \mathrm{ml}$ was used as a coating reagent. Quantification was carried out using $50 \mu \mathrm{l}$ of aliquots $1 / 10$ to $1 / 4000$ serially diluted of each standard antibody isotype. Serum samples were diluted 1/25000 in PBS.

\section{Statistical analysis}

Densitometric intensities of sera from bGH Tg mice were expressed in units of standard deviation from the mean intensity of the group of control sera. A single value of mean intensity per serum was calculated by averaging the corrected intensities in all determinations. A serum was considered to be immunoreactive when its mean intensity was higher than $95 \%(P<0 \cdot 05)$ of the mean intensity of the control sera. Statistical analyses of frequencies were performed by the $\chi^{2}$ test. Logistic regression analysis, relative incidences and $95 \%$ confidence intervals (CI) were calculated as previously described (Morris \& Gardner 1988).

\section{Results}

Histological study of the knee of $b \mathrm{GH} \mathrm{Tg}$ mice

At 6 months old, bGH Tg mice showed impaired movement. We assessed the histological characterization of the proximal tibia region of 40 male and female animals over 6 months and compared results with those obtained from control animals. As expected, the chondroepiphysis of $\mathrm{bGH} \mathrm{Tg}$ mice was twice the size of the control mice. In Fig. 1A , the three characteristic zones of a normal articular cartilage were observed in control animals: the radial zone 
$(\mathrm{r})$, which involves a small number of primary cartilage cells; the transitional zone $(t)$, composed of primary cells at the stage of proliferation and acquiring the chondrocyte phenotype; and the superficial zone (s), which is composed of two lines of elongate chondrocytes and constitutes the upper gliding surface of joints. In contrast to control mice, articular cartilage was altered in all the bGH $\mathrm{Tg}$ mice examined. Discontinuous regions of cartilage composition were observed along the tibial joint: regions presenting a significant reduction in thickness (Fig. 1C), regions where articular cartilage was absent (data not shown), regions with a regular thickness (Fig. 1D) and regions with clefts (Fig. 1B). The chondrocyte pattern of articular cartilage was altered in bGH Tg mice. As can be observed in Fig. $1 \mathrm{C}$ and $\mathrm{D}$, in the deep radial zone $(\mathrm{r})$ chondrocytes were usually disorganized in comparison with control cartilage. Significant changes were also detected in the transitional zone $(t)$ : the number of chondrocytes at the end of clonal expansion (two nuclei), aligned chondrocytes and single differentiated chondrocytes were significantly reduced and the number of hypertrophic chondrocytes increased (Fig. 1C), while regions of articular cartilage with a normal thickness (Fig. 1D) presented an increased number of chondrocytes at all stages of clonal expansion and hypertrophied chondrocytes. Interestingly, the superficial zone(s) of articular cartilage disappeared in bGH Tg mice (Fig. 1C and $\mathrm{D})$. This zone is composed of highly hypertrophied chondrocytes with large dense nuclei instead of the two lines of elongate chondrocytes present in control mice.

The synovia of bGH Tg mice (Fig. $2 \mathrm{~B}$ and $\mathrm{C}$ ) also presented profound alterations in comparison with control animals (Fig. 2A). A reduced number of adipocytes (a) and a thickening of the synovial lining layer (lt) was generally observed in comparison with control synovial tissue (Fig. 2, A versus B). Vasculitis and/or arteritis and inflammatory infiltrations were occasionally observed although pannus was often present (Fig. 2C).

\section{Presence of anti-nuclear antibodies in $b \mathrm{GH} \mathrm{Tg}$ mice}

The effect of chronic circulating $\mathrm{GH}$ on the immune system was assessed by determining in bGH $\mathrm{Tg}$ mice the main serological parameters described in murine models of autoimmune diseases (Theofilopoulos \& Dixon 1985). Four- to six-month-old Tg-positive mice of both sexes were studied for the presence of self-antibodies. A total of 24 sera from $\mathrm{Tg}$ mice (both sexes) and 24 sera from control mice were probed on NIH $3 \mathrm{~T} 3$ cell preparations. More than $90 \%(22 / 24)$ of the tested sera from Tg-positive mice reacted to the nucleus of NIH 3T3. Conversely, only 1 of the 24 control sera reacted to the NIH $3 \mathrm{~T} 3$ nucleus. These results prompted us to study the incidence of anti-ss and anti-dsDNA antibodies in bGH Tg mice compared with control mice. A systematic study of immunoreactivity to ssDNA and dsDNA was then performed, using sera from 30 control and $60 \mathrm{bGH}$ Tg mice. Densitometric data were
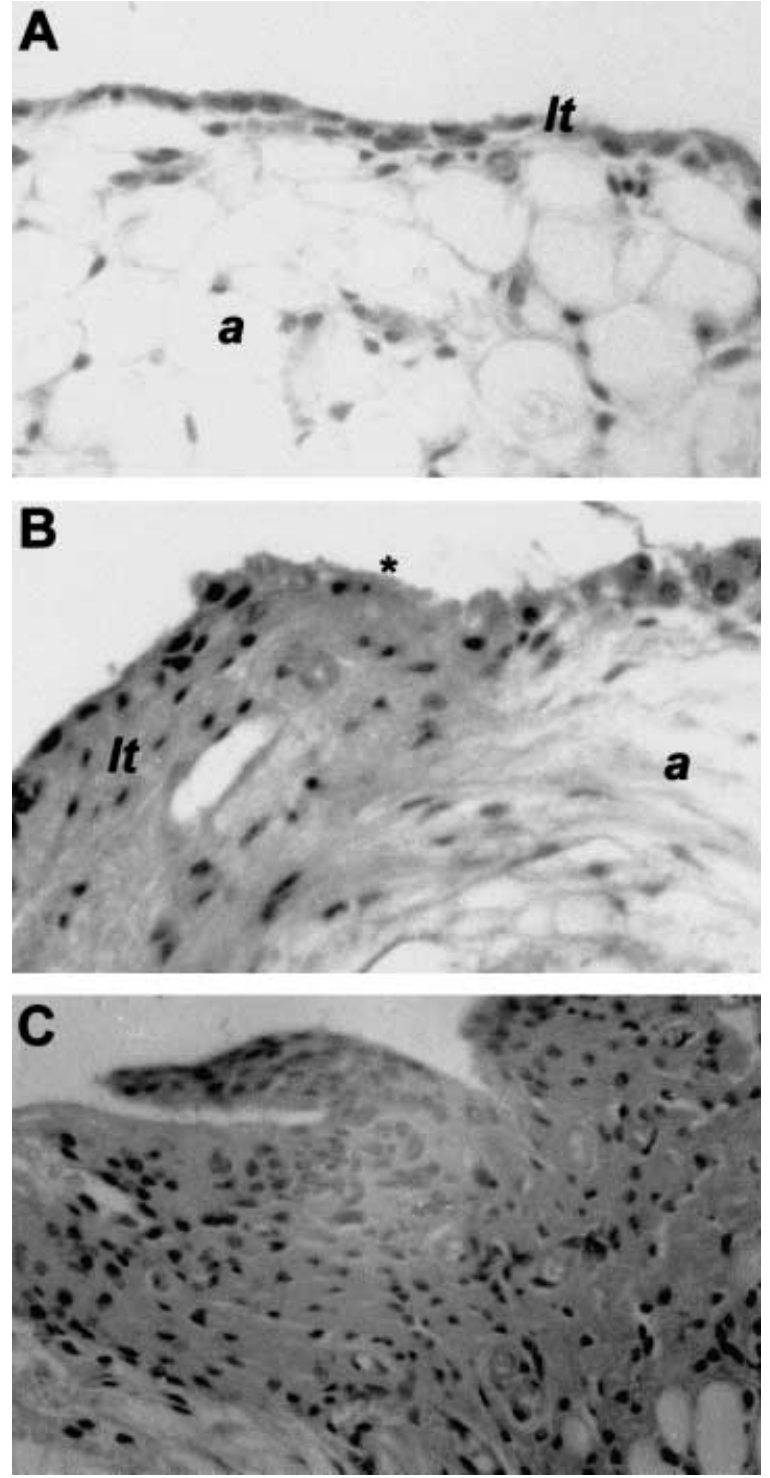

Figure 2 Synovial examination. Synovial tissue of bGH Tg mice (B) shows a reduced number of adipocytes (a) and thickening of synovial lining tissue (It) with uncovered zones of cells $\left(^{*}\right)$ when compared with control mice (A). Pannus observed in bGH Tg mice $(C) . \times 1000$ magnification.

quantified and processed as described in the Material and Methods section. The results obtained are summarized in Fig. 3. We found immunoreactivity to ssDNA in $33 \%$ $(P<0.02)$ and to dsDNA in $25 \%(P<0 \cdot 05)$ of bGH Tg. Sera of these mice yielded a staining intensity above the 95\% confidence level compared with control group.

We also studied whether anti-ssDNA and dsDNA antibody levels were affected by age considering three age groups (2 months (Y), 4-6 months (A) and 6-8 months $(\mathrm{O})$ ) of bGH Tg animals. The frequency of immunoreactive sera to ssDNA at the $95 \%$ confidence level was 


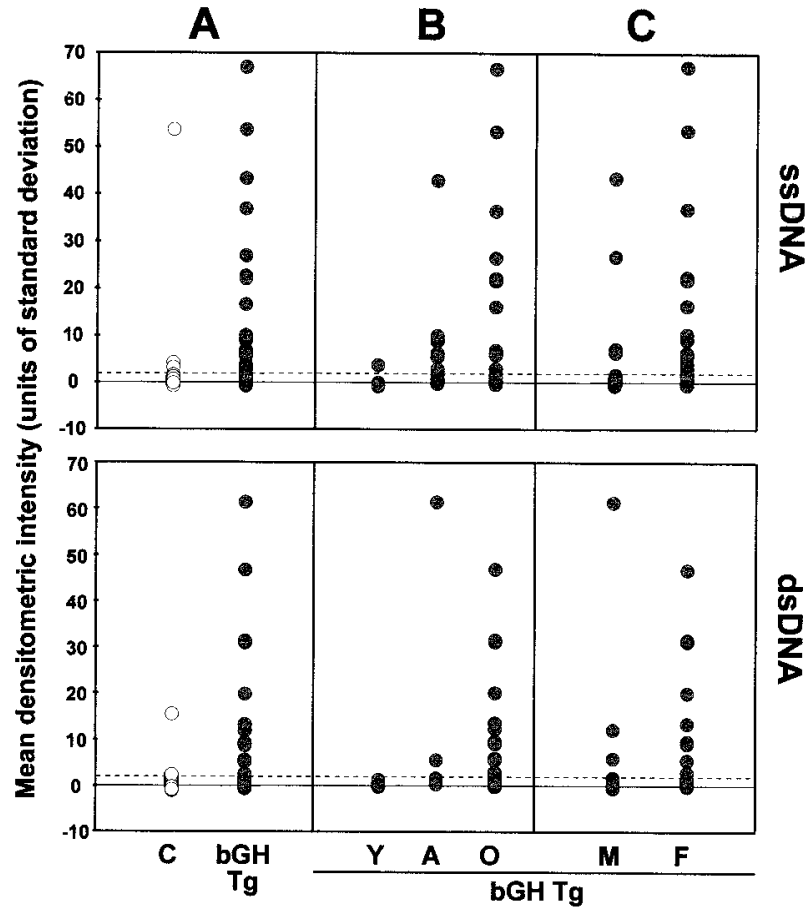

Figure 3 Incidence of anti-ssDNA and anti-dsDNA antibodies. Mean immunoreactivity to ssDNA and dsDNA of control $(O)$ and bGH Tg sera ( ). Circles represent the mean immunoreactivity of each serum in terms of densitometric intensity. Horizontal, broken lines indicate the $95 \%$ superior confidence limits of the mean. In A, sera of control (C) and bGH Tg mice are shown. In B, sera of bGH Tg mice at different ages are shown: Young (Y), 2 months; Adult (A), 4-6 months; Old (O), 6-8 months. In C, sera of bGH Tg mice, both males $(\mathrm{M})$ and females $(\mathrm{F})$, are shown.

found to be significantly higher in both adult (A) and old $(\mathrm{O}) \mathrm{Tg}$ mice groups in comparison to that of the young $(\mathrm{Y})$ Tg mice group $(P<0 \cdot 04)$ and there was no significant difference between frequencies in the adult and old $\mathrm{Tg}$ mice groups $(P>0 \cdot 05)$. On the other hand, the frequency of immunoreactive sera to dsDNA was found to gradually increase with age considering the above-mentioned three groups of bGH Tg mice and was, therefore, analysed using a logistic regression model. This analysis yielded a significant $2 \cdot 8$-fold $(1 \cdot 4-5 \cdot 8,95 \% \mathrm{CI})$ and $8 \cdot 0$-fold $(1 \cdot 9-33 \cdot 6$, 95\% CI) increase in the incidence of immunoreactive sera of the adult and old groups of $\mathrm{Tg}$ mice considering the group of young mice as a reference group. The correlation between sex and immunoreactivity to ssDNA and dsDNA was found to be higher in females than males $(P<0 \cdot 005$ and $P<0.05$ respectively) (Fig. 3 ).

\section{Anti-70K antibodies in bGH $\mathrm{Tg}$ mice}

The above results suggested the development of an autoimmune disorder. To further analyse this possibility, we tested for the presence of other autoimmune markers such
A

\section{Control bGH Tg}
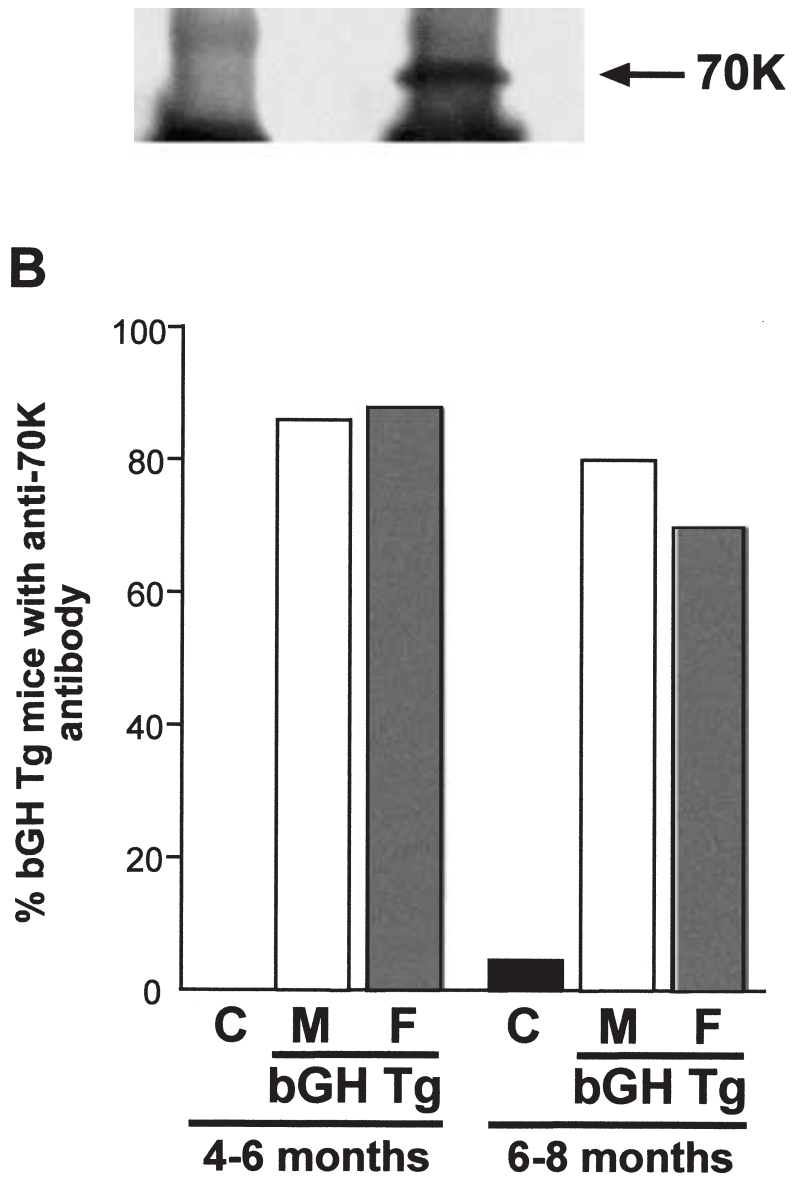

Figure 4 Incidence of anti-70K component of $U 1$ antibodies. $100 \mu \mathrm{l}$ of serum samples from bGH Tg mice (72 animals) and control mice (68 animals) of both sexes were reacted with proteins isolated from mouse liver nuclei. Immune complexes were analysed by Western blotting and probed for $70 \mathrm{~K}$ protein using MAb H111. Detection was carried out chemiluminescently. The upper part of the figure shows the results of a representative determination where the $70 \mathrm{~K}$ is indicated $(\mathrm{A})$. The lower part of the figure shows the results expressed as percentages (B).

Anti-70K antibodies in sera of bGH Tg mice in adult, 4-6-monthand old, 6-8-month-old groups of males $(\mathrm{M})$ and females $(\mathrm{F})$ are shown. Anti-70K antibodies in sera of control (C) mice were only observed in females $(4 / 68)$ of the $6-8$-month-old group.

as anti-70K (Lerner \& Steinz 1979). The 70K protein is a component of $\mathrm{U} 1$ small nuclear ribonucleoprotein (U1snRNP) which plays an essential role in pre-mRNA splicing (Kastner et al. 1992). To this end, sera were used to precipitate proteins extracted from isolated mouse liver nuclei and the presence of the $70 \mathrm{~K}$ protein in immune complexes detected using MAb 111 by Western blotting. In Fig. $4 \mathrm{~A}$ a determination of $70 \mathrm{~K}$ is shown as an example. 
Table 1 Immunoglobulin typing. The levels of IgM and IgG subclasses in young and old bGH Tg mice and control mice of both sexes (12 animals of each category) were determined by ELISA using a kit from Southern Biotechnology. Quantifications were carried out using the corresponding standard Ig. Data are means \pm S.E.M. Underlined values: $P<0.05$ versus control values

Serum Immunoglobulin Levels $(\mathrm{mg} / \mathrm{ml})$

\begin{tabular}{|c|c|c|c|c|c|c|c|c|}
\hline & \multicolumn{4}{|l|}{ Young } & \multicolumn{4}{|l|}{ Old } \\
\hline & M & $\mathrm{F}$ & M & $\mathrm{F}$ & M & $\mathrm{F}$ & M & $\mathrm{F}$ \\
\hline $\lg M$ & $0 \cdot 11 \pm 0.02$ & $0 \cdot 08 \pm 0 \cdot 01$ & $0 \cdot 17 \pm 0 \cdot 02$ & $0.29 \pm 0.03$ & $0 \cdot 47 \pm 0 \cdot 02$ & $0 \cdot 30 \pm 0 \cdot 00$ & $0 \cdot 58 \pm 0 \cdot 12$ & $0 \cdot 44 \pm 0.08$ \\
\hline $\lg G$ & $0 \cdot 81 \pm 0 \cdot 04$ & $0.90 \pm 0.02$ & $1 \cdot 04 \pm 0 \cdot 17$ & $\overline{1 \cdot 36 \pm 0 \cdot 18}$ & $1 \cdot 95 \pm 0.04$ & $1 \cdot 66 \pm 0.05$ & $1 \cdot 76 \pm 0 \cdot 18$ & $1 \cdot 88 \pm 0 \cdot 19$ \\
\hline $\lg _{1}$ & $0 \cdot 40 \pm 0.03$ & $0.48 \pm 0.02$ & $\overline{0 \cdot 43 \pm 0 \cdot 12}$ & $\overline{0.63 \pm 0.05}$ & $0.69 \pm 0.02$ & $0 \cdot 41 \pm 0 \cdot 01$ & $0 \cdot 56 \pm 0 \cdot 20$ & $0 \cdot 65 \pm 0 \cdot 13$ \\
\hline $\operatorname{lgG}_{3}$ & $0 \cdot 10 \pm 0 \cdot 01$ & $0.08 \pm 0.01$ & $0 \cdot 15 \pm 0.01$ & $0 \cdot 17 \pm 0 \cdot 01$ & $0 \cdot 29 \pm 0 \cdot 01$ & $0 \cdot 28 \pm 0 \cdot 01$ & $0 \cdot 29 \pm 0 \cdot 01$ & $0.39 \pm 0.08$ \\
\hline
\end{tabular}

We observed that, at early ages (2 months and both sexes) the presence of anti-70K antibodies in sera of bGH $\mathrm{Tg}$ mice was not significant (results not shown). However, the percentage of bGH $\mathrm{Tg}$ mice displaying anti-70K antibodies in the 4-6- and 6-8-month-old groups of males and females was surprisingly high (Fig. 4B). The incidence of anti-70K antibodies was $85-90 \%$, irrespective of age and sex. In control mice, only the 6-8-month-old group of animals showed a sporadic presence of anti-70K antibodies (4/68).

\section{Increased levels of $\operatorname{IgM}, \operatorname{IgG}_{2 a}$ and $\operatorname{Ig} G_{3}$}

The level of circulating Ig subclasses in young (2-3 months old) (24 animals) and old (8-9 months old) (24 animals) male and female bGH Tg mice compared with controls was also studied. As shown in Table 1, young Tg males presented 1.5-, 6- and 1.5-fold increases in $\operatorname{IgM}, \operatorname{IgG}_{2 a}$ and $\mathrm{IgG}_{3}$ respectively, while these increases were approximately double in Tg females (3.6-, 8- and 3.6-fold, respectively). The total $\mathrm{IgG}$ concentration in young bGH $\mathrm{Tg}$ mice increased by $23 \%$ in males and $40 \%$ in females. Nevertheless, these differences were not evident in bGH $\mathrm{Tg}$ old mice since control mice already displayed high levels of immunoglobulins (Table 1).

\section{Discussion}

The results of this work show that bGH Tg mice develop arthritic joints. Both articular cartilage and synovial tissues showed severe damage including a generalized loss of the normal zonal structure of cartilage and frequent cartilage clefts, altered chondrocyte growth/differentiation pattern, a decrease in synovial adipocytes and proliferation of synovial lining cells. Moreover, we show that bGH Tg mice develop self-antibodies in serum including anti-70K, anti-ssDNA, anti-dsDNA and altered immunoglobulin typing as a function of age and female sex that suggest an autoimmune-like disease. Articular and immune disease can be interpreted as independent phenomena as a consequence of a direct effect of sustained high GH/IGF-I levels, or articular damage dependent on the development of an autoimmune-like disease.

The role of GH/IGF-I in joints can be explained by increasing evidence that the integrity of joints is maintained by the balance of cytokine-driven processes in bone, cartilage and synovium. Unregulated or excess influences of these molecules are thought to play a part in the pathophysiology of joint diseases (Westcott \& Sharif 1996). However, the synovia appears to play a predominant role in diarthrosis. A thickening of synovial lining tissue and an altered rate of some cytokine production by these cells has been shown in both patients with osteoarthritis and rheumatoid arthritis (Gay et al. 1993, Smith et al. 1997). bGH $\mathrm{Tg}$ mice show proliferation of synovial lining cells similar to that observed in the synovial membranes from patients with severe osteoarthritis and may produce an altered rate of cytokine in the knee joint. On the other hand, synovial hyperplasia, inflammation and autoimmune phenomena are well known hallmarks in rheumatoid arthritis (Gay et al. 1993). Since inflammatory infiltrates are rarely seen in synovial tissue of bGH $\mathrm{Tg}$ mice, this suggests that the alterations observed could be related to an osteoarthritis process. However, a rheumatoid arthritis process can not be excluded given that a T-cell independent pathway has been demonstrated where synovial lining cells attach, invade and destroy cartilage by the production of matrix-degrading enzymes (Müller-Ladner et al. 1996).

The results of this work also show that in bGH $\mathrm{Tg}$ cartilage the: (a) deorganization of zonal structure and (b) profound alterations in chondrocyte growth/ differentiation processes, are consistent with a severe osteoarthritis. Systemically and locally produced growth factors and hormones regulate cartilage metabolism. Alterations in levels of these factors or in their activity can influence the pathogenesis or cartilage destruction in 
arthritic joints (Verschure et al. 1996b). Cartilage alterations in bGH Tg mice can be interpreted in this sense. The specific role of GH in cartilage is unknown although $\mathrm{GH}$ receptors are present in chondrocytes (Nilsson et al. 1990). In addition, it has been shown that IGF-I is the most important growth factor that balances chondrocytes proteoglycan synthesis and catabolism (Verschure et al. 1996a, Van den Berg 1997). Clear zonal correlation has been detected between IGF-I receptor and proteoglycan synthesis which is lost in osteoarthritis (Verschure et al. 1996b). Moreover, increased levels of IGF-I and IGFbinding protein-3 have been determined in synovial fluids of patients with rheumatoid arthritis (Matsumoto et al. 1998). Thus, the cartilage damage of $\mathrm{bGH} \mathrm{Tg} \mathrm{mice} \mathrm{is}$ likely produced by the effect of sustained high GH/IGF-I levels. As cartilage destruction is a major complication of arthritic processes, bGH Tg mice constitute a suitable model with which to improve our understanding of the biology and pathology of articular cartilage.

The serological determinations performed in this work show that bGH Tg mice develop an autoimmune-like process, that this immune disorder appears in adult animals and is more relevant in the females. The mechanism by which autoimmune disorders are generated is not well understood, although several hypotheses have been proposed (Van Noort \& Amor 1998). In fact, it is likely that most autoimmune diseases are multifactorial in origin. The results suggest that the immune disorder observed in bGH $\mathrm{Tg}$ mice could be mediated by the effect of sustained high GH/IGF-I levels. The expression of GH receptor and IGF-I receptor in immune cell system has been reported as well as the induction of lymphopoiesis and haematopoiesis in vivo and in vitro (Kooijman et al. 1995, Gagnerault et al. 1996, Clark 1997, Mello-Coelho et al. 1998). Thus, it can be suggested that sustained GH/IGF-I levels are involved in an increased lymphoiesis and cell survival, thereby suppressing apoptosis of self-reactive lymphocytes. In this way, chronic high GH/IGF-I levels in Tg mice would produce an autoimmune-like pathology that closely resembles that described in MRL mice (Cohen \& Eisenberg 1991). Furthermore, recent reports showing the anti-apoptotic effect of GH and IGF-I support this notion (Kulik \& Weber 1998, Haeffner et al. 1999) and would also explain the subclinical activation of lupus nephritis reported by $\mathrm{GH}$ administration (Yap et al. 1998). However, further works need to be performed in order to understand the mechanism underlying the autoimmune-like process displayed in $\mathrm{Tg}$ mice.

In summary, our results show that bGH $\mathrm{Tg}$ mice develop a spontaneous autoimmune-like disorder accompanied by profound alterations in joints. Whether both phenomena are related or not, and the specific role of GH/IGF-I, remain to be elucidated. Given that cartilage destruction is a major complication of osteoarthritis and rheumatoid arthritis we therefore propose that $\mathrm{bGH} \mathrm{Tg}$ mice are a suitable and reliable model for investigating
GH/IGF-I-driven processes in joint tissues and in immune cells and the pathophysiology of joints.

\section{Acknowledgements}

The authors are grateful to Dr Marie-Catherine PostelVinay and Dr Elena Baixeras for their help and critical review of the manuscript and to Dr Jesús Vázquez for his expert statistical advice. We thank Javier Palacín for his expertise in animal care and Mariano Bautista for the artwork. This work was supported by grants from DGICYT, FIS and the Ramón Areces Foundation.

\section{References}

Barkan AL 1992 Acromegaly. Trends in Endocrinology and Metabolism 3 205-210.

Clark R 1997 The somatogenic hormones and insulin growth factor-1: stimulators of lymphopoiesis and immune function. Endocrine Reviews 18 1-23.

Cohen PL \& Eisenberg RA 1991 Lpr and gld: single gene models of systemic autoimmunity and lymphoproliferative disease. Annual Review of Immunology 9 243-269.

Frohman LA 1996 New insights into the regulation of somatotrope function using genetic and transgenic models. Metabolism 45 1-3.

Gagnerault M-C, Postel-Vinay M-C \& Dardenne M 1996 Expression of growth hormone receptors in murine lymphoid cells analyzed by flow cytofluorometry. Endocrinology 137 1719-1726.

Gay S, Gay RE \& Koopman WJ 1993 Molecular and cellular mechanisms of joint destruction in rheumatoid arthritis: two cellular mechanisms explain joint destruction? Annals of Rheumatic Diseases 52 S39-S47.

Gonzalo JA, Mazuchelli R, Mellado M, Frade JMR, Carrera AC, vonKobbe C, Mérida I \& Martínez AC 1996 Enterotoxin septic shock protection and deficient $\mathrm{T}$ Helper 2 cytokine production in growth hormone transgenic mice. Journal of Immunology 157 3298-3304.

Haeffner A, Deas O, Mollereau B, Estanquier J, Mignon A, Haeffner-Caravillon N, Senik A \& Hirsoh F 1999 Growth hormone prevents human monocytic cells from Fas-mediated apoptosis by up-regulating Bcl-2 expression. European Journal of Immunology 29 334-344.

Kastner B, Kornstädt U, Bach M \& Lührmann R 1992 Structure of the small RNP particle U1: Identification of the two structural protuberances with RNP-antigens A and 70K. Journal of Cellular Biology 116 839-849.

Kelly PA, Ali S, Rozaskis M, Goujon L, Nagaro M, Pellegrini I, Gould D, Edery M, Finidori J \& Postel-Vinay MC 1993 The growth hormone/prolactin receptor family. Recent Progress in Hormone Research 48 123-164.

Kooijman RK, Scholtens LE, Rijkers GT \& Zegers BJ 1995 Differential expression of type I insulin-like growth factor receptors in different stages of human T cells. European Journal of Immunology 25 931-935.

Kulik G \& Weber MJ 1998 Akt-dependent and -independent survival signaling pathways utilized by insulin-like growth factor 1 . Molecular and Cellular Biology 18 6743-269.

Lerner MR \& Steinz JA 1979 Antibodies to small nuclear RNAs complexed with proteins are produced by patients with systemic lupus erythematosus. Proceedings of the National Academy of Sciences of the USA 76 5495-5497.

Li S, Crenshaw EB, Rawson EJ, Simmons DM, Swanson LW \& Rosenfeld MG 1990 Dwarf locus mutants lacking three pituitary cell types result from mutations in the pou-domain gene pit-1. Nature 347 528-533. 
Lin SC, Lin CR, Gukovsky I, Lusis A, Sawchenko PE \& Rosenfeld MG 1993 Molecular basis of the little mouse phenotype and implications for cell type-specific growth. Nature 364 208-213.

Mankin HJ, Mow VC, Buckwalter JA, Ianotti JP \& Ratliffe A 1994 Form and function of articular cartilage. In Orthopaedic Basic Science, pp 1-44. Ed. SR Simon. American Academy of Orthopedic Surgeons.

Matsumoto T, Yamashita S \& Rosenfeld RG 1998 Increased levels of IGF-I and IGFBP-3 in synovial fluids of patients with rheumatoid arthritis. Endocrine Journal 45 S141-S144.

McGrane MM, Yun JS, Moorman AFM, Lamers WH, Hendrick GK, Arafah BM, Park EA, Wagner TE \& Hanson RW 1990 Metabolic effects of developmental, tissue-, and cell-specific expression of a chimeric phosphoenolpyruvate carboxykinase (GTP)/bovine growth hormone gene in transgenic mice. Journal of Biological Chemistry 265 22371-22379.

Mello-Coelho V, Gagnerault M-C, Souberbielle J-C, Strasburger CJ, Sabini W, Dardenne M \& Postel-Vinay M-C 1998 Growth hormone and its receptor in human thymic cells. Endocrinology 139 3837-3842.

Montecino-Rodríguez E, Clark RG, Collins JL \& Dorshkind K 1996 Defective B cell development in Snell dwarf mice results from endocrine defects that can be corrected by thyroxine treatment. Journal of Immunology 157 3334-3340.

Montecino-Rodríguez E, Clark RG, Powell-Braxton L \& Dorshkind K 1997 Primary B cell development is impaired in mice with defects of the pituitary/thyroid axis. Journal of Immunology 159 2712-2719.

Morris JA \& Gardner MJ 1988 Calculating confidence intervals for relative risks (odds ratios) and standardised ratios and rates. British Medical Journal 296 1313-1316.

Müller-Ladner U, Kriegsmann J, Franklin BN, Matsumoto S, Geiler T, Gay RE \& Gay S 1996 Synovial fibroblasts of patients with rheumatoid arthritis attach to and invade normal human cartilage when engrafted into SCID mice. American Journal of Pathology 149 1606-1615.

Murphy WJ, Durum SK, Anver MR \& Longo DL 1992a Immunologic and hematologic effects of neuroendocrine hormones. Studies on DW/J Dwarf mice. Journal of Immunology 148 3799-3805.

Murphy WJ, Durum SK \& Longo DL $1992 b$ Role of neuroendocrine hormones in murine T cell development. Growth hormone exerts thymopoietic effects in vivo. Journal of Immunology 149 3851-3857.
Nilsson A, Calsson B, Mathews L \& Isaksson OG 1990 Growth hormone regulation of the growth hormone receptor mRNA in cultured rat epiphyseal chondrocytes. Molecular and Cellular Endocrinology 70 237-246.

Powell-Baxton L, Hollingshead C, Warburton M, Dowd S, Pittse-Meek S, Dalton D, Gillett N \& Stewart TA 1993 IGF-I is required for normal embryonic growth in mice. Genes and Development 7 2609-2627.

Quaife CJ, Mathews LS, Pinkert CA, Hammer RE, Brinster RL \& Palmiter RD 1989 Histopathology associated with elevated levels of growth hormone and insulin-like growth factor I in transgenic mice. Endocrinology 124 40-48.

Smith MD, Triantafillon S, Parker A, Youssef PR \& Coleman M 1997 Synovial membrane inflammation and cytokine production in patients with early osteoarthritis. Journal of Rheumatology 24 365-371.

Theofilopoulos AN \& Dixon FS 1985 Murine models of systemic lupus erythematosus. Advances in Immunology 37 269-390.

Van den Berg WB 1997 Lessons for joint destruction from animals models. Current Opinions in Rheumatology 9 221-228.

Van Noort JM \& Amor S 1998 Cell biology of autoimmune diseases. International Review of Cytology 178 127-205.

Verschure PJ, Van Noorden CJ, Van Marle J \& Van den Berg WB 1996a Articular cartilage destruction in experimental inflammatory arthritis: insulin-like growth factor-1 regulation of proteoglycan metabolism in chondrocytes. Histochemical Journal 28 835-857.

Verschure PJ, Marle JV, Joosten LA, Helsen MM, Lafeber FP \& Van den Berg WB $1996 b$ Localization of insulin-like growth factor-1 receptor in human normal and osteoarthritic cartilage in relation to proteoglycan synthesis in man. British Journal of Rheumatology 35 1044-1055.

Westcott CI \& Sharif M 1996 Cytokines in osteoarthritis: mediators or markers of joint destruction. Seminars in Arthritis and Rheumatism 25 254-272.

Yap HK, Loke KY, Murugasu B \& Lee BW 1998 Subclinical activation of lupus nephritis by recombinant human growth hormone. Pediatric Nephrology 12 133-135.

Received 23 September 1999

Accepted 16 December 1999 